\title{
Editorial
}

\section{Jana Zvárová}

Editor-in-Chief

Biomedical informatics is a burgeoning field, with important applications and implications throughout the biomedical world and healthcare delivery. The European Journal of Biomedical Informatics $(E J B I)$ is reacting on the great European need to share the information in the multilingual and multicultural European area.

EJBI opens for the field of biomedical informatics a new model of electronic publishing. EJBI is publishing accepted peer-reviewed papers in English and other languages simultaneously. This opens new possibilities for faster transfer of scientific-research pieces of knowledge of many European countries to a large international community of biomedical researchers, physicians, other health personnel and citizens. Moreover, the journal now enables to make results of scientific-research work and practical experiences of foreign specialists accessible to wider health public in a more comprehensible way in each European country.

The aim of the editorial board is to reach the highest scientific level of the journal and show the best practices of biomedical informatics applications to wide readership. The European editorial board is composed from outstanding specialists in the field of biomedical informatics. We believe that their activities for EJBI will contribute to propagation of journal's good credit. The editorial board also presumes that presentation of English versions of scientific papers with their professional translations to other languages will significantly contribute to unification of applied scientific terminology.

EJBI is now a Schattauer related journal. You may find more information in Editorial of Methods of Information in Medicine, Issue 22008. 